\title{
Seroprevalence of Hepatitis B Infection among First-Time Blood Donors in Faridpur, Bangladesh: A Cross-sectional Study
}

Tonmoy Biswas, ${ }^{1,2}$ Sunil Kumar Biswas. ${ }^{3}$

\begin{abstract}
Background: Hepatitis B infection is a global threat for people of all age groups and is common in Bangladesh and other South Asian countries. Blood donors and blood donation can present important risk for hepatitis B infection. Our objective was to identify seroprevalence of hepatitis B virus among blood donors in Faridpur, Bangladesh. Methods: A cross-sectional study was conducted among 719 blood donors in the Faridpur district of Bangladesh from April to July 2013. Data was collected by non-probability convenient sampling maintaining inclusion and exclusion criteria. Face-to-face interview, blood grouping test, and hepatitis B surface antigen (HBsAg) screening were conducted. Results: About $30 \%$ of the blood donors were between 19 and 23 years of age, and $87.5 \%$ of them were males. Two-thirds $(64.1 \%)$ of the donors were replacement donors, while the remaining $35.9 \%$ of them were voluntary donors. The overall seropositivity of HBsAg was found to be $1.5 \%$. All infected blood donors were males. Hepatitis B infection was more prevalent in the 34-38 years age group and least prevalent among those older than 48 years of age. About $2 \%$ of replacement blood donors were infected with hepatitis B virus, compared to $0.7 \%$ among voluntary blood donors. Conclusion: Hepatitis B infection among blood donors is relatively lower than in other high-risk groups for hepatitis B infection in Bangladesh. Predominance of HBsAg among older adult groups, replacement donors, and the male gender can be a matter of public health concern.
\end{abstract}

Keywords: Hepatitis B; Blood Transfusion; Blood Donors; Bangladesh (Source: MeSH-NLM).

About the Author: Tonmoy Biswas recently graduated from Faridpur Medical CoIlege, University of Dhaka, Bangladesh with a Bachelor of Medicine, Bachelor of surgery (MBBS) degree.
Submission: May 24, 2015 Acceptance: Oct 17, 2015 Publication: Apr 10, 2016 Process: Peer-reviewed

\section{Introduction}

Hepatitis B virus (HBV) is a small DNA virus that belongs to the Hepadna virus family and infects nearly 240 million people worldwide. HBV infection is transmitted mostly during infancy and childhood, even though people of all age groups are equaIly affected.' The prevalence rate of HBV infection in Bangladesh is in the same magnitude as the Indian Subcontinent and Middle East at 2-5\% (Available from: http://www.who.int/mediacentre/factsheets/fs204/en, updated 2015 Mar; cited 2015 May 24), although a much higher hepatitis B surface antigen (HBsAg) positivity (5.5\%) has been reported among the general population of Savar, a semi-urban area located near the capital of Bangladesh. ${ }^{2}$ The lifetime risk of acquiring HBV infection in the mentioned areas is $20-60 \%$, with about $40 \%$ of the world population residing in the said regions.'

Viral liver diseases are significant causes of morbidity in Bangladesh, and a large proportion of acute viral hepatitis, chronic liver disease, hepatocellular carcinoma, and post transfusion hepatitis cases in Bangladesh could be attributed to HBV infections. ${ }^{3}$ Early detection is necessary to reduce the risk and impact of viral liver diseases. A number of diagnostic tests could be performed to detect the presence of HBV in the blood. While antibody to the hepatitis B core antigen (anti-HBC) is an important biomarker in the detection of HBV infection, HBSAg is the most trustworthy biological biomarker of $\mathrm{HBV}^{4}$ Most of the previous studies in Bangladesh have used HBsAg as the biomarker. ${ }^{5-8}$
Various studies have been conducted among the known major high-risk groups to examine the prevalence of the life-threatening HBV infection in Bangladesh, but the prevalence of HBV infection in the general population has received little attention. ${ }^{5-17}$ To estimate the prevalence of $\mathrm{HBsAg}$ among the general population, we conducted a study among the first-time blood donors at two voluntary blood donation organizations in Faridpur, Bangladesh. Specifically, the aims of the study were to determine the overall seroprevalence of HBV among blood donors and to identify the prevalence of HBsAg among different age groups, genders, blood groups, and donor types.

\section{Methods}

\section{Study Setting and Participants}

A cross-sectional study of first-time blood donors was conducted at two voluntary blood donation agencies in Faridpur, Bangladesh with approval from the Faridpur Medical College Hospital. These two voluntary blood donation agencies were the local branches of the respective national agencies and handled most of the blood donation in Faridpur. Males and females between the ages of 18 years and 65 years were eligible to donate blood, with an average donation amount of $350 \mathrm{ml}$ as stipulated in national guidelines. We collected data on demographic variables such as age and sex, blood group, type of donation, and serological screening results from April 1, 2013 to July 31, 2013.

Replacement donors (family members, friends, or relatives of the patients whom the blood would be donated to) and

Faridpur Medical College, University of Dhaka, Faridpur, Bangladesh.

American University of Sovereign Nations, Scottsdale, Arizona, USA.

3 Bangabandhu Sheikh Mujib Medical Universtiy, Dhaka, Bangladesh.

Correspondence:

Tonmoy Biswas

Address: Faridpur Medical College, Dhaka-Faridpur Hwy, Faridpur, Bangladesh

Email: tshekhor@yahoo.com 
voluntary blood donors (people who donated blood without expecting any favor in return or in voluntary blood donation camps) of both genders who donated blood in the defined time period went through blood screening procedures, and inclusion and exclusion criteria were applied to select participants for the study. Specifically, the inclusion criteria were: (1) donating blood for the first time, having no previous record or history of donation; (2) normal findings on general physical examination; (3) mentally capable; and (4) provided informed consent for blood donation and participation in the study. Exclusion criteria were same as those for blood donation: (1) not within the age limit eligible for blood donation; (2) a pulse rate of more than 120/min, as blood donation might be risky; (3) a systolic blood pressure higher than $180 \mathrm{mmHg}$, as blood donation might be risky; (4) having clinical symptoms of anemia; (5) any history of surgery or dental treatment within the last six months; (6) blood transfusion within the last six months; (7) women during menstruation, not suitable due to blood loss; (8) alcohol consumption within the last 72 hours, as serum alcohol level might be significant; and (9) any known history of exposure to hepatitis B. The flow of participants through the study is presented in Figure 1.

Figure 1. Selection of Participants for the Study

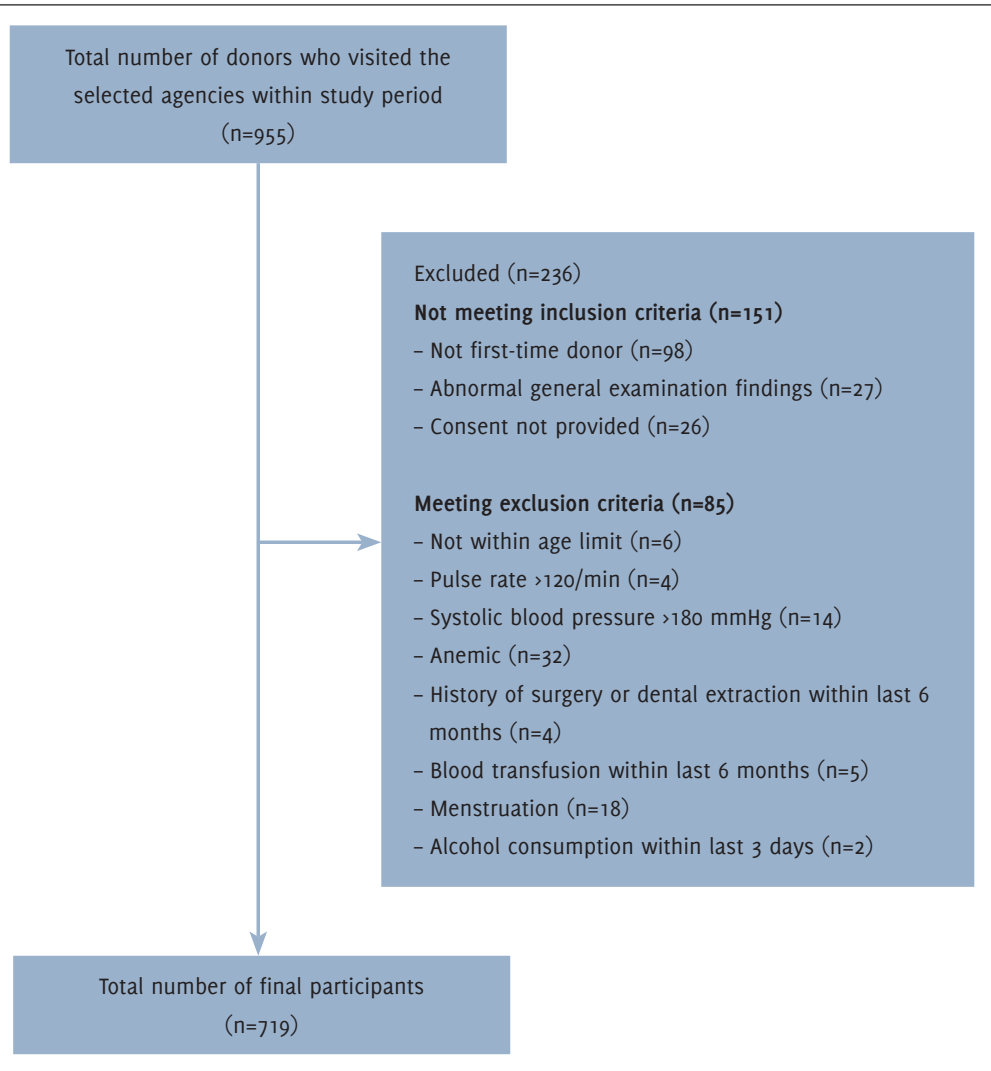

Sampling Technique and Sample Size

Respondents were selected through non-probability convenient sampling. All donors who attended the two agencies in the defined period who met the inclusion criteria were included after considering the exclusion criteria. For calculation of sample size, we used a prevalence figure of $50 \%$ (which would generate the biggest sample size with the same a piori criteria), as no recent studies had been conducted within the last three years or in regions with similar settings to our study area. Using the equation for minimum sample size estimation of single proportion, $n=Z^{2} p q / d^{2}$, where $z=1.96, p=0.5, q=1-p=0.5, d=0.05$, the minimum sample size required was 384.16 (rounded to 384). We used a sample size of 719 to account for the possible non-responses.

\section{Data Collection}

Face-to-face interviews were conducted with the participants for about 10 minutes by experts using questionnaires to collect information about their personal status, eligibility, and some demographic variables including age, sex, religion, residential area, and any relationship with the patient to whom the blood was donated to. The questionnaire was approved by a professor of public health from Faridpur Medical College. Questions related to inclusion and exclusion criteria were asked for selection purpose. Pulse rates were measured by experts, and blood pressures were measured three times with the average calculated to minimize measurement errors. Then blood grouping was done to confirm their blood group. After proper aseptic measures, blood was collected from the middle cubital vein and kept in a test tube at $-20^{\circ} \mathrm{C}$ for preservation.

\section{Serological Screening}

At room temperature, the test tubes with blood samples were centrifuged at 3,000 rotations per minute for 8-10 minutes, and clear plasma was collected from the upper part of the fluid for screening. To examine the presence of HBsAg in the blood, HBsAg test strip and serum/plasma kits (Atlas Medical, UK), which were rapid chromatographic immunoassays for the qualitative detection of HBSAg in human serum/plasma, were used. If test result was positive, the test was repeated once for confirmation purpose. The test was done by a medical technician and was approved by a physician. The blood samples were marked in a unique manner to prevent mistakes and biases. Data pertaining to the patients were given the same identification number as of their blood samples to minimize errors.

\section{Data Management}

Data management and screening was done by master tabulation. Simple descriptive analyses were done using Microsoft Excel 2010. Data was then imported into IBM SPSS Statistics for Windows version 18 (IBM Corp., Armonk, New York, USA) for further analyses. The analysis was approved by a statistician.

\section{Ethical Measures}

Informed consent was obtained from the participants after the rationale and aim of the study as well as their ability to withdraw from participation voluntarily were explained. Proper privacy and confidentiality was maintained throughout the process. The research protocol was approved by the local ethical committee of Faridpur. The STrengthening of Reporting of OBservational studies in Epidemiology (STROBE) was followed in preparing this paper. ${ }^{18}$

\section{Results}

Table 1 shows the characteristics of the 719 blood donors who participated in our study. Young donors between 19 and 23 years of age accounted for the largest proportion (29.5\%) of the participating donors. The vast majority of donors $(87.5 \%)$ were males. Most 
Table 1. Characteristics of Blood Donors in Faridpur, Bangladesh

\begin{tabular}{lcc}
\hline Donor characteristics & $\begin{array}{c}\text { Number of donors } \\
(\mathrm{N}=719)\end{array}$ & Percentage (\%) \\
Age (years) & 28 & 3.9 \\
$<19$ & 212 & 29.5 \\
$19-23$ & 152 & 21.1 \\
$24-28$ & 109 & 15.2 \\
$29-33$ & 69 & 9.6 \\
$34-38$ & 85 & 11.8 \\
$39-43$ & 39 & 5.4 \\
$44-48$ & 25 & 3.5 \\
$>48$ & & 87.5 \\
Cender & 629 & 12.5 \\
Male & 90 & \\
Female & &
\end{tabular}

Marital status

$\begin{array}{lcc}\text { Single } & 224 & 31.1 \\ \text { Married } & 495 & 68.9 \\ \text { Place of living } & & \\ \text { Same district } & 638 & 88.8 \\ \text { Outside the district } & 81 & 11.2\end{array}$

Religion

$\begin{array}{lcc}\text { Muslim } & 630 & 87.6 \\ \text { Hindu } & 88 & 12.3 \\ \text { Christian } & 1 & 0.1\end{array}$

$\begin{array}{lll}\text { Type of donor } & & \\ \text { Voluntary } & 258 & 35.9 \\ \text { Replacement } & 461 & 64.1\end{array}$

Blood group

\begin{tabular}{lcc}
$\mathrm{A}+$ & 173 & 24.1 \\
$\mathrm{~B}+$ & 283 & 39.3 \\
$\mathrm{O}+$ & 174 & 24.2 \\
$\mathrm{AB}+$ & 63 & 8.8 \\
Others (rhesus negative) & 26 & 3.6 \\
HBsAg result & & \\
Positive & 11 & 1.5 \\
Negative & 708 & 98.5 \\
\hline
\end{tabular}

$(88.8 \%)$ of the donors were from the region/district in which the two voluntary blood donation organizations were located. Voluntary donors constituted $35.9 \%$ of all donors, while the remaining $64.1 \%$ were replacement donors.

The blood group composition of the donors was as follows: 173 (24.1\%) were A positive, $283(39.3 \%)$ were B positive, $174(24.2 \%)$ were 0 positive, $63(8.8 \%)$ were $A B$ positive, and the remaining 26 (3.6\%) were of rhesus-negative groups. The proportions of voluntary donors among A positive donors, B positive donors, 0 positive donors, and rhesus-negative donors were $51.1 \%, 27.2 \%, 38.9 \%$, and $50.0 \%$, respectively.
Among all the screened blood samples, 11 (1.5\%) blood donors were HBsAg-positive. All HBsAg-positive donors were male. The seroprevalence of HBsAg among different blood groups was as follows: $1.7 \%$ in A positive donors, $0.7 \%$ in B positive donors, and $2.3 \%$ among 0 positive donors. Seroprevalence of $\mathrm{HBSAg}$ in different age groups is shown in Figure 2. HBV prevalence were $1.9 \%$ among the replacement donors and $0.7 \%$ among the voluntary donors.

\section{Discussion}

The main purpose of our study was to determine the prevalence of HBV infection among first-time blood donors in Faridpur, Bangladesh. The result revealed a HBsAg seropositivity of $1.5 \%$ among all first-time donors, similar to findings from previous studies conducted among blood donors in Khulna and in Rangamati, Bangladesh, which estimated a prevalence of 1.1$1.4 \% .{ }^{19,20}$ In contrast, previous studies among high-risk groups of transfusion-transmitted infections (TTIs) in Bangladesh reported higher prevalences of HBV infection, ranging from 3.8\% to $9.7 \%{ }^{1,9,11,17,21-23}$ The prevalence of HBV infection among blood donors in our study was similar with those reported by studies conducted in nearby countries (India, Pakistan, and China) in $2013 .{ }^{24-26}$ In comparison, the worldwide seroprevalence of HB$\mathrm{SAg}$ is $3.6 \% .^{27}$

In our study, we found that HBV infection was more common among donors between 34 and 38 years of age. This might be due to known high-risk behaviors among this age group, including history of previous blood transfusions, occupational or accidental injuries, and higher frequency of sexual behaviors. A recent study in a country adjacent to Bangladesh-Nepal-showed that TTIs were more common among those aged between 21 and 30 years. ${ }^{28}$ One possible explanation for the difference could be that the Nepal study included all TTIs, while our study focused on hepatitis B infection. Nonetheless, both our study and the Nepal study found that hepatitis B infection was more prevalent among males. B positive donors constituted the biggest group of donors, but the seroprevalence of HBV infection was higher among 0 positive donors and A positive donors, although the differences were not statistically significant. HBV infection was also more common among replacement donors (1.9\%) than voluntary donors (0.7\%). More studies are required to examine the reasons for these findings.

In this study, we also captured sociodemographic backgrounds of all blood donors. Our results showed that young age groups (of 19 to 23 years) were more enthusiastic in blood donation, concurring with previous findings., ${ }^{1,29}$ Additionally, the vast majority of the donors were males. This could possibly be attributed to the fact that in Bangladesh, females are more occupied with household works and hence have less time for blood donation. This finding is supported by a study in a neighboring country with similar socioeconomic condition. ${ }^{28}$

The study had some limitations. As this is a cross-sectional study, risk factors and natural histories of HBV infection among participating donors could not be determined. We are aware that our study, conducted in a small community/area, might not be representative of a larger community/area. Nonetheless, we were able to assess the distribution of different variables such as age, sex, blood groups, and type of blood donation and 
Figure 2. HBsAg Seroprevalence in Different Age Groups

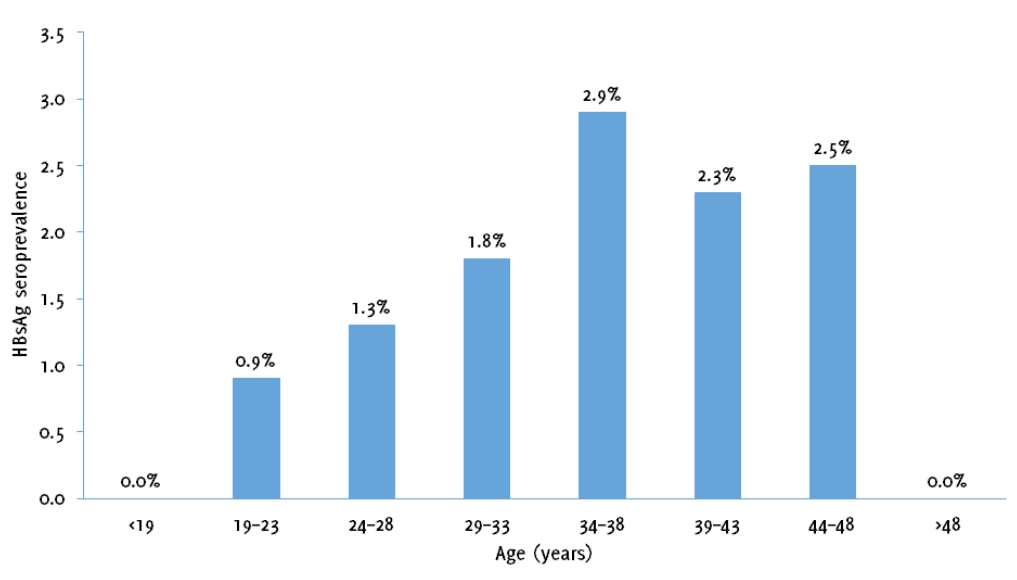

measure the frequency distribution of HBV infection among different groups.

In conclusion, the prevalence of HBV infection among blood donors in Faridpur, Bangladesh is not negligible. The rate was similar to those reported in other regions of Bangladesh, which vary between $1.1 \%$ and $1.6 \%$. HBsAg positivity of blood donors in Bangladesh was slightly greater than those of India, Nepal, and China but lower than that in Pakistan. The proportion of HBV infection in blood donors was much lower than other high-risk groups reported in Bangladesh. In view of these findings, we recommend that proper screening measures for HBSAg and other TTIs should be practiced before blood donations. People from all eligible age groups and genders should be encouraged to donate blood, while risk factors for TTIs should be effectively assessed and prevented. Infected blood donors should be informed, managed, and treated promptly. Appropriate policies should be implemented to ensure the safety of blood donation and blood transfusions, for example, through public awareness campaigns. More research studies are needed to examine the risk factors, epidemiological features, trends, and preventive measures for HBV infection in Bangladesh.

\section{References}

1. Tibbs CJ, Smith HM. Clinicians' guide to viral hepatitis. London: Arnold; 2001.

2. Mahtab MA, Rahman S, Karim MF, Khan M, Foster G, Solaiman S, et al. Epidemiology of hepatitis $B$ virus in Bangladeshi general population. Hepatobiliary Pancreat Dis Int. 2008 Dec;7(6):595-600.

3. Khan M, Ahmed N. Seroepidemiology of HBV and HCV in Bangladesh [abstract]. Int Hepatol Commun. 1996 May;5(1):27-9.

4. Deinhardt F. Serum markers of hepatitis viruses in natural disease and after vaccination. Prog Liver Dis. 1982;7:451-67.

5. Islam MN, Islam KM, Islam N. Hepatitis-B virus infection in Dhaka, Bangladesh. Bangladesh Med Res Counc Bull. 1984 Jun;10(1):1-6.

6. Rumi MA, Begum K, Hassan MS, Hasan SM, Azam MG, Hasan KN, et al. Detection of hepatitis $B$ surface antigen in pregnant women attending a public hospital for delivery: implication for vaccination strategy in Bangladesh. Am J Trop Med Hyg. 1998 Aug;59(2):318-22.

7. Mustafa M, Islam MN, Rahman M, Salauddin AK. Prevalence of hepatitis B surface antigen (HBSAg) among parenteral drug abusers at Dhaka. Bangladesh Med Res Counc Bull. 1989 Jun;15(1):1-7.

8. Ahmad Q, Chowdhury SG, Islam MN, Khan FD, Alam MR, Miah AH. HBsAg amongst unscreened operated patients. Bangladesh Med Res Counc Bull. 1991 Jun; $17(1): 11-6$

9. Sattar H, Islam MN. Hepatitis B virus markers among the prostitutes of Dhaka. Bangladesh Med Res Counc Bull. 1996 Apr;22(1):8-11.

10. Khan WI, Sultana R, Rahman M, Akhter H, Haq JA, Ali L, et al. Viral hepatitis: recent experiences from serological studies in Bangladesh. Asian Pac J Allergy Immunol. 2000 Jun;18(2):99-103.

11. Sabin KM, Rahman M, Hawkes S, Ahsan K, Begum L, Black RE, et al. SexuaIly transmitted infections prevalence rates in slum communities of Dhaka, Bangladesh. Int J STD AIDS. 2003 Sep;14(9):614-21.

12. Rumi MA, Siddiqui MA, Salam MA, Iqbal MR, Azam MG, Chowdhury AK, et al. Prevalence of infectious diseases and drug abuse among Bangladeshi workers. Southeast Asian J Trop Med Public Health. 2000 Sep;31(3):571-4.

13. Rahman M, Amanullah, Sattar H, Rahman M, Rashid HA, Mollah AS. Sero-epidemiological study of hepatitis $B$ virus infection in a village. Bangladesh Med Res Counc Bull. 1997 Aug;23(2):38-41.

14. Khan M, Haq SA, Ahmed N, Matin MA. Etiology and clinical profile of hepatocellular carcinoma in Bangladesh. Bangladesh Med Res Counc Bull. $1997 \mathrm{Apr} ; 23(1): 16-24$.

15. Hawkes S. Commentary: Human immunodeficiency virus and hepatitis in Bangladesh: widespread or targeted prevention strategies? Int J Epidemiol. 2001 Aug;30(4):885-6.

16. Laskar MS, Harada N, Khan F. Prevalence of hepatitis B surface antigen (HBsAg) in Viqarunnessa noon girls' school children in Dhaka, Bangladesh. Cent Eur J Public Health. 1997 Dec;5(4):202-4.

17. Ashraf H, Alam NH, Rothermundt C, Brooks A, Bardhan P, Hossain L, et al. Prevalence and risk factors of hepatitis $B$ and $C$ virus infections in an impoverished urban community in Dhaka, Bangladesh. BMC Infect Dis. 2010 Jul 15;10:208.

18. von Elm E, Altman DG, Egger M, Pocock SJ, Gotzsche PC, Vandenbroucke JP; STROBE Initiative. The Strengthening the Reporting of Observational Studies in Epidemiology (STROBE) statement: guidelines for reporting observational studies. PLOS Med. 2007 Oct 16;4(10):e296.

19. Rudra S, Chakrabarty P, Hossain MA, Akhter H, Bhuiyan MR. Seroprevalence of hepatitis B, hepatitis C, HIV infections in blood donors of Khulna, Bangladesh. Mymensingh Med J. 2010 0ct;19(4):515-9.

20. Dewan C. Prevalence of hepatitis B and C virus seropositivity among tribal and non-tribal voluntary blood donors of Rangamati, Bangladesh. J Univers Coll of Med Sci. 2013;1(4):33-6.

21. Gibney L, Saquib N, Metzger J, Choudhury P, Siddiqui M, Hassan M. Human immunodeficiency virus, hepatitis $B, C$ and $D$ in Bangladesh's trucking industry: prevalence and risk factors. Int J Epidemiol. 2001 Aug;30(4):878-84. 22. Shirin T, Ahmed T, Iqbal A, Islam M, Islam MN. Prevalence and risk factors of hepatitis $B$ virus, hepatitis $C$ virus, and human immunodeficiency virus infections among drug addicts in Bangladesh. J Health Popul. Nutr. 2000 Dec;18(3):145-50.

23. de Francisco A, Hall AJ, Alam N, Hawkes S, Azim T. Hepatitis B infection in Bangladeshi mothers and infants. Southeast Asian J Trop Med Public Health. 1999 Jun;30(2):296-8.

24. Agarwal N, Chatterjee K, Coshic P, Borgohain M. Nucleic acid testing for blood banks: an experience from a tertiary care centre in New Delhi, India. Transfus Apher Sci. 2013 Dec;49(3):482-4.

25. Zaheer HA, Saeed U, Waheed Y, Karimi S, Waheed U. Prevalence and trends of hepatitis $B$, hepatitis $C$ and human immunodeficiency viruses among blood donors in Islamabad, Pakistan 2005-2013. J Blood Disord Transf. 2014;5(6):217.

26. Liu GC, Sui GY, Liu GY, Zheng Y, Deng Y, Gao YY, et al. A Bayesian meta-analysis on prevalence of hepatitis $B$ virus infection among Chinese volunteer blood donors. PloS One. 2013 Nov 13;8(11):e79203.

27. Schweitzer A, Horn J, Mikolajczyk RT, Krause G, Ott JJ. Estimations of worldwide prevalence of chronic hepatitis $B$ virus infection: a systematic review of 


\section{Original Article}

data published between 1965 and 2013. Lancet. 2015 0ct 17;386(10003):154655. 28. Pandeya DR. P3.253 Sero prevalence of HIV, hepatitis B, hepatitis $C$ and syphilis among blood donors in Kathmandu, Nepal. Sex Transm Infect. 2013;89(Suppl 1):A227-8.

29. Ahad MA, Bakar MA, Nazmul Ahsan HA. Pattern of ABO and Rhesus(Rh) blood group among blood donors. J Teach Assoc. 2002;15(2):68-70.
30. Talukder SI, Das RK. Distribution of $A B O$ and Rh blood groups among blood donors of Dinajpur district of Bangladesh. Dinajpur Med Coll J. 2010 Jul; $3(2): 55-8$.

31. Sultana R, Rahman Z, Helali AM, Yousuf R, Mustafa S, Salam A, et al. Study of $A B O$ and Rh-D blood groups among the common people of capital city of Bangladesh. Int J Pharm Pharm Sci. 2013;5(3):814-6.

\section{Acknowledgments}

We are grateful to Sandhani at Faridpur Medical College Hospital and Medicine Club at Faridpur Medical College Hospital (both of which are branches of two blood donation agencies) for helping out in data collection, serological tests, and blood grouping tests. We are also thankful to Dr. Sambita Chakravorty (medical intern) and Sumit Paul Anik (fifth-year medical student) for their contribution in protocol management and data collection.

Conflict of Interest Statement a Funding

The Authors have no funding, financial relationships or conflicts of interest to disclose.

\section{Author Contributions}

Conceptualization, Contribution of patients or study materials, Data collection, Statistical advice, Data analysis and interpretation, Writing: TB. Funding acquisition, Critical revision of the manuscript, Approval of the final version, Administrative/technical advice: SKB.

Cite as:

Biswas T, Biswas SK. Seroprevalence of hepatitis B infection among first-time blood donors in Faridpur, Bangladesh: a cross-sectional study. Int J Med Students. 2016 Jan-Apr;4(1):9-13. 